\title{
Analysis on the General Conception and Planning of the Road Trip Campsite along the Land Silk Road in China
}

\author{
Yanjun $\mathrm{Li}^{1, \mathrm{a}^{*}}$, Minglan $\mathrm{Ge}^{2, \mathrm{~b}}$ \\ ${ }^{1}$ Shaanxi University of Science \& Technology, Xi'an 710021, China \\ ${ }^{2}$ Xi'an Longhu Property Service Co., Ltd, Xi'an 710054, China
}

\begin{abstract}
This article is based on the cultural background of the land section of the "Silk Road" and the surrounding status quo research basis, combined with its own characteristics of tourism resources, folk culture and traffic conditions, establish a self-driving camping site system in the five provinces of Shaanxi, Gansu, Ningxia, Qinghai and New Zealand on the domestic section of the "Silk Road". This paper summarizes the current situation and constraints of campsites in each province through data collection, data analysis and field investigation. On this basis, we put forward the overall construction and planning ideas of the camp. The purpose is to scientifically, reasonably and orderly plan the construction scheme of road trip routes, camping sites and campsites along the Silk Road.This will further promote the healthy development of tourism and cultural experience in the areas along the Silk Road, provide convenient and safe travel routes and recreation environment for tourists, but also improve the economy and people's living standards in the areas along the route.
\end{abstract}

\section{INTRODUCTION}

With the reform and opening up, the economy and living standards of the Chinese people continue to improve, resulting in an increase in the number of private cars. Therefore, as a new form of tourism-"self-driving tour" has become one of the forms of travel for people. With its own global influence and profound history, the Silk Road has become a popular tourist destination for tourists all over the world due to its multi-ethnic, multi-religious culture, spectacular natural landscape, especially those road trip tourists who want to closely experience nature and have a challenging spirit. Therefore, the tourism routes and campsites matching road trip appeared passively, and gradually developed into a new type of tourism experience (Zhai \& Lv, 2017).

According to statistics, at present, in the more economically developed areas of China, road trip campsites are in full swing, especially in the coastal and central and eastern regions (Lin \& Lin, 2018). In contrast, the road trip campsites in Northwest China has not been put on the planning and construction agenda. Although there is an individual case, it is not on a large scale. Therefore, in order to support the large-scale development of the western region, do a good job in economic construction and enhance the happiness index of the people, the government issued a relevant guidance document in August 2015: "Speed up the construction of road trip campsites in ethnic minority areas, along the Silk Road and key tourist areas in the Yangtze River Economic Belt."

\section{DEVELOPMENT STATUS OF ROAD TRIP CAMPSITES IN CHINA ALONG THE SILK ROAD}

At present, the planning and construction of camps in Shaanxi, Gansu, Ningxia, Qinghai and Xinjiang along the Silk Road are still relatively scattered, with a late start, slow development and a large gap compared with the coastal and central and eastern regions. Since June 2014, the areas along the Silk Road have been ranked first in the "China Road Trip Route" (Ma, 2015). After that, the relevant policies of "Belt and Road Initiative" have been introduced, which have made tourism in Northwest China have a good momentum of development. At the same time, many provinces and regions also realize the value and significance of road trip tourism to drive the local economy and have gradually been paid more and more attention to.

The natural scenery, long historical background and cultural status along the Silk Road have become important tourism resources. With the change of people's travel concept, abundant holiday time and the convenience of opening of main traffic lines, the number of camps covering five provinces and regions has increased by the end of 2017 compared with 2016 (Figure 1).

Comprehensively analyze the construction of existing campsites in various provinces along the "Silk Road". We can clearly see that there is a lack of macro overall planning. The lack of a unified management model,

\footnotetext{
Corresponding author: aylw55668@163.com

b915809452@qq.com
} 
unscientific distribution of campsites, fragmentation of a system, and excessive concentration all have many negative impacts on scenic spots. For example, most of the campsites in Qinghai are built around the Qinghai Lake Scenic Area; developers rarely formal, mostly for the private construction, but also lack of overall, unified, safe construction standards. In addition, there are also large- scale campsites in the provinces along the line, and all of them are equipped with wooden house villa area, RV camp, tent camp, comprehensive service body and supporting landscape facilities. However, their architectural forms in public areas are generally the same, lacking regional and cultural characteristics. But there are also great cases, such as Camp 151 in Erlang Sword Scenic Area, Qinghai. Each room in the camp is named after a representative scenic spot in Qinghai Province, which is also an alternative way of publicizing "Greater Qinghai". In addition, the Yongjing Public Aviation Brigade and the Yellow River Three Gorges Self-driving Tour Base in Gansu Province is also an excellent representative. It was rated as the "China's Most Potential Camping Site" from 2017 to 2018. The camp takes green, healthy and leisure as its business philosophy, and sets up viewing pavilion, veranda, flower trellis, greenbelt and ecological surrounding water system. It has become a self- driving camp integrating accommodation, catering, ecological tourism, cultural experience, leisure and entertainment. However, there are few such typical cases along the silk road.

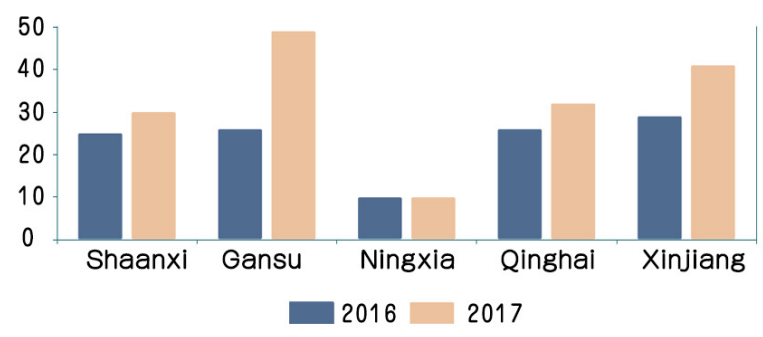

Figure 1. Statistics of number of road trip campsites in five northwest provinces along the Silk Road from 2016 to 2017 (Source: painted by the author)

\section{INFLUENCING FACTORS OF ROAD TRIP CAMPSITES IN CHINA ALONG THE SILK ROAD}

\subsection{Favorable Factors}

\subsubsection{National Policy Support}

The National Tourism Administration issued the "Car Road Trip Campsites Development Plan" in May 2017, creating a classic road trip route of "three circles and two lines": around the coast, the central and eastern regions, through the eastern and western parts and covering the "Belt and Road Initiative" land Silk Road (Figure 2). At the same time, the five provinces along the Silk Road have also issued relevant policies to support them. For example, Shaanxi issued "Several Opinions on Further Promoting Tourism Investment and Consumption" in February 2016, proposing a unified plan for the construction of campsites for road trip tours. In June 2016, Gansu proposed the goal of making Gansu Province a "international RV camping destination" in the "Silk Road Gansu Transportation RV Camping Site Development Plan" (Zhu \& Xue, 2019). In October 2016, Qinghai built a campsite system in the province based on the "Qinghai Province Road Trip Tourism Product Development Plan" and built a high-standard road trip campsite and landscape corridor system. In March 2017, Ningxia issued the "the 13th Five-Year Global Tourism Development Plan for Ningxia Hui Autonomous Region" and guided the construction of road trip camps, and actively created tourism products with the ancient charm. In June 2017, Xinjiang clearly pointed out in the "Work Plan for Promoting the Construction and Management of road trip RV Camps in Xinjiang Uyghur Region" that different types of campsites should be built on the basis of environmental protection, combined with the actual situation of the development of road trip tourism.

\subsubsection{Improvement of Highway Traffic Network}

In the past ten years, with the support of the national development policy, the construction of highway traffic network in Northwest China has developed rapidly. The improvement of the construction quality of national highways, provincial highways and county highways has greatly increased the frequency of people's travel, and made travel more convenient, safe and comfortable. As a result, a group of self-driving travel groups with companies, families, and friends as the unit emerged. While enjoying self-driving travel, people broaden their horizons, increase their knowledge, and narrow the distance between people.

\subsubsection{Steady Progress in the Great Western Development and Economic Construction}

The implementation of the "Belt and Road Initiative" policy affects the development of tourism economy in the five northwestern provinces to a great extent. According to statistics from 2013 to 2017 , the gross domestic product of the western region increased by 4.4 trillion yuan, with an average annual growth rate of $8.8 \%$, and its proportion in China increased from $19.8 \%$ to $20.0 \%$, which laid a solid economic foundation for the construction of the camp. 


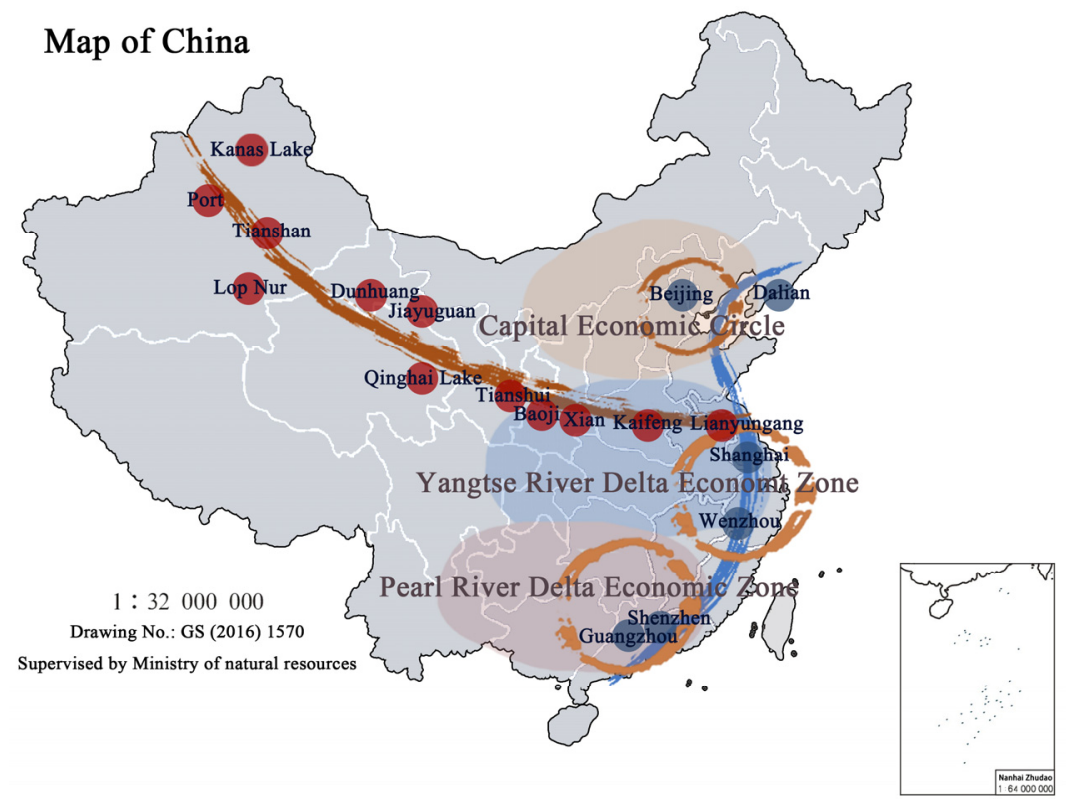

Figure 2. Schematic diagram of "three circles and two lines" road trip route planning (Source: painted by the author)

\subsubsection{Innovation and Charm of Road Trip Campsites}

As a self-challenge, road trips not only provide tourists with opportunities to stay close to nature, enjoy exotic scenery and religious culture, but also spread the spirit of the Silk Road and promote the economic and cultural development of the five provinces. In addition, camping is a form of outdoor leisure life that integrates sightseeing, entertainment and accommodation. It can provide travelers with a place to relax themselves and socialize. According to relevant statistics, although self-driving campsites are in the primary stage in China, their development potential and room for growth are huge (Figure 3).
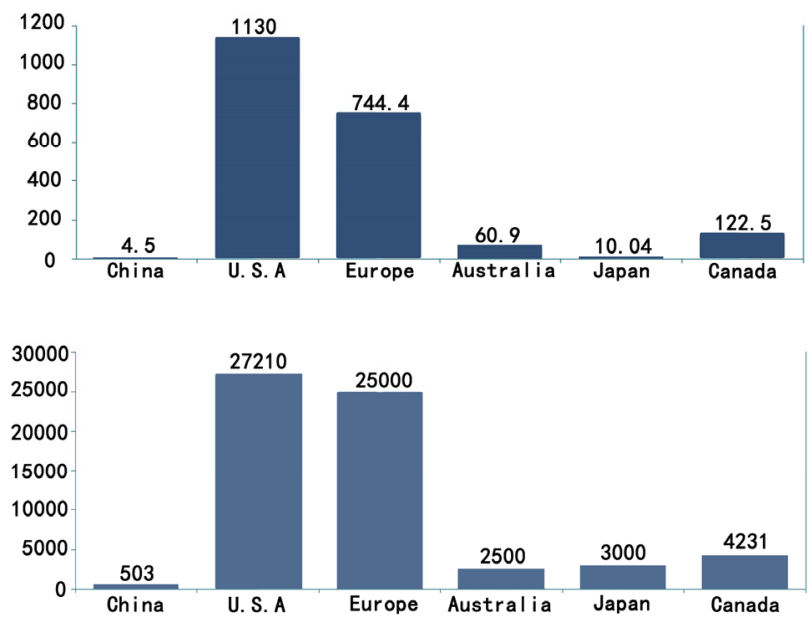

Figure 3. Schematic diagram of the number of RVs and campsites in the world from 2016 to 2017 (Source: painted by the author)

\subsubsection{Rich Tourism Resources and Diverse Cultural Activities}

The Silk Road, as an important transportation route lasting for thousands of years, has played a great role in the development of social civilization (Lin \& Wang, 2006). A unique tourism resource is formed, which is also the motivation and source of self-driving tourists to choose the Silk Road journey.

There are many magnificent natural and cultural landscapes in the five provinces along the route. Such as the desert, grassland, snow river, swamp, caster landform, salt lake and other natural landscapes and rare flora and fauna near the silk road. As well as the ancient city of Loulan, Dunhuang Mogao Grottoes, Kumbum Monastery, Aywangs dwellings, yurts and other cultural landscapes. In addition, there are more than 40 ethnic minorities, including Kazakh, Uyghur, Hui, Tibetan, Manchu ethnic groups and splendid folk activities.

\subsection{Restricting Factors}

The main constraints on the development of the "Silk Road" road trip are as follows: First, the five provinces lack coordinated policies and mechanisms. Second, the relevant laws and regulations are not perfect and the service guarantee is not in place. Third, due to the vast area, the campsites are scattered and the infrastructure is not perfect. Fourth, the difference between slack season and peak season is obvious. Fifth, The destination is blocked and the traffic is inconvenient. Sixth, the number of enterprises participating in the development is small and the management team and professionals are insufficient (Ge \& Li, 2018).

(1) Lack of unified policies and mechanisms. Although the provinces along the Silk Road have introduced relevant policies, most of them are planned 
within the province due to geographical restrictions. This has led to differences in the management of the campsites in the five provinces. In addition, there are common problems of improper ecological environment protection, shortage of construction land, and inadequate facility construction and maintenance management.

(2) Laws and regulations are not perfect and services are not in place. At present, the planning design and laws and regulations for the domestic camp of the "Silk Road" have not yet been formed. The construction of scattered camps is not standardized, and security issues cannot be completely resolved, and industry management is basically in an unorganized state. Especially in the uninhabited areas of Qinghai and Xinjiang, the inconvenient transportation and harsh natural environment make safety problems extremely prominent.

(3) The campsites are scattered and the infrastructure is not complete. The five provinces and regions along the Silk Road are vast and distant, with few landscapes and long distances between them. The current situation is that the number of camps along the route is small and the layout is uneven. Camp no business relationship between each other, can not generate complete network of services and so on, failed to form a good momentum of development. In addition to the technical problems of water, electricity, sewage and garbage disposal in camps far away from the city, life infrastructure, vehicle supply, vehicle maintenance and other issues also restrict the travel routes to a large extent.

(4) Significant differences between low and peak seasons. These five provinces are all located in Northwest China. The winters are long and cold, with high temperatures and little rain in summer, and sandstorms and tornadoes often occur. This has led to the reality that the peak season for self-driving travel is short and the off-season is long. When tourists travel during peak seasons, it is also easy to cause road congestion, unavailable restaurants, and shortage of camps. In the low season, a large number of service facilities in scenic spots and camps will be idle.

(5) Poor accessibility. Compared with the developed areas in the central and eastern coastal areas, the development of transportation facilities in Northwest China is still relatively poor. For example, the road network between scenic spots, scenic spots and surrounding cities, and cities have not been fully formed, and there is a lack of safe, convenient and fast traffic arteries. In addition, there are many uninhabited areas in Northwest China, such as deserts, Gobi deserts, basins, natural grasslands, plateaus, and icebergs in Ningxia, Gansu, and Xinjiang that restrict the possibility of vehicles entering.

(6) The companies involved in the development are few and small in scale, lacking management teams and professionals. The more common tourism development companies in China include Beijing Tourism Group, Hong Kong China Travel International Travel Service Co., Ltd., 318 Group and other campground chain brands. However, the development scale of camps along the Silk Road was small and the management level was low. Companies often lack investment funds and are unable to formulate complete construction investment plans. It is difficult to meet the long-term development needs of the camp. At present, most of the employees in the camp are temporarily employed in the surrounding towns or villages. They have not received vocational training and present problems such as insufficient professionalism and poor service quality.

\section{OVERALL CONCEPTION AND STRATEGY OF ROAD TRIP CAMPSITES IN CHINA ALONG THE SILK ROAD}

\subsection{Concept: Promote the Silk Road Culture and Spirit}

The "Silk Road" was a business route from ancient Chang'an to Europe via land in the Han and Tang Dynasties. It has made great contributions to the cultural, commercial and technological exchanges of countries along the route and has attracted worldwide attention. In addition, along the ancient Silk Road is a gathering area of many ethnic groups, with great differences in cultural background, religious beliefs, ethnic customs, etc. Its majestic and diverse natural scenery attracts scholars and travel enthusiasts at home and abroad to favor the area. Therefore, the planning of campsites must take the inheritance and promotion of Silk Road traditional culture as the core, and build each campsite into a unique classic route with distinctive regional characteristics and systematic characteristics.

\subsection{Goal: On the Basis of Human, Valuing the Nature}

The construction of road trip camp should be based on "people-oriented and scientific planning" as the core. We should pay attention to the full service of roads, camps, facilities, rescue services, guidance systems and traffic radio station. At the same time, we should pay attention to the original protection and utilization of campsite development, so as to achieve the interdependence and harmonious coexistence between man and nature.

In the site selection, to "Respect for nature and primeval landscapes" as the goal. Without destroying or less destroying the original geological and geomorphological conditions of non-cultivated land, non-intact meadows, saline-alkali land, beach land, lakeside, icebergs, etc., the site selection should be scientific, reasonable, environmentally friendly, convenient and safe.

\subsection{Strategy: Unified Planning of the Five Provinces to Jointly Seek Development}

On the whole, we should adhere to the macro unification, break the regional restrictions, establish the management coordination group and formulate the unified standards. For example, uniformly plan the selection criteria, application area, necessary facilities, shopping stores, 


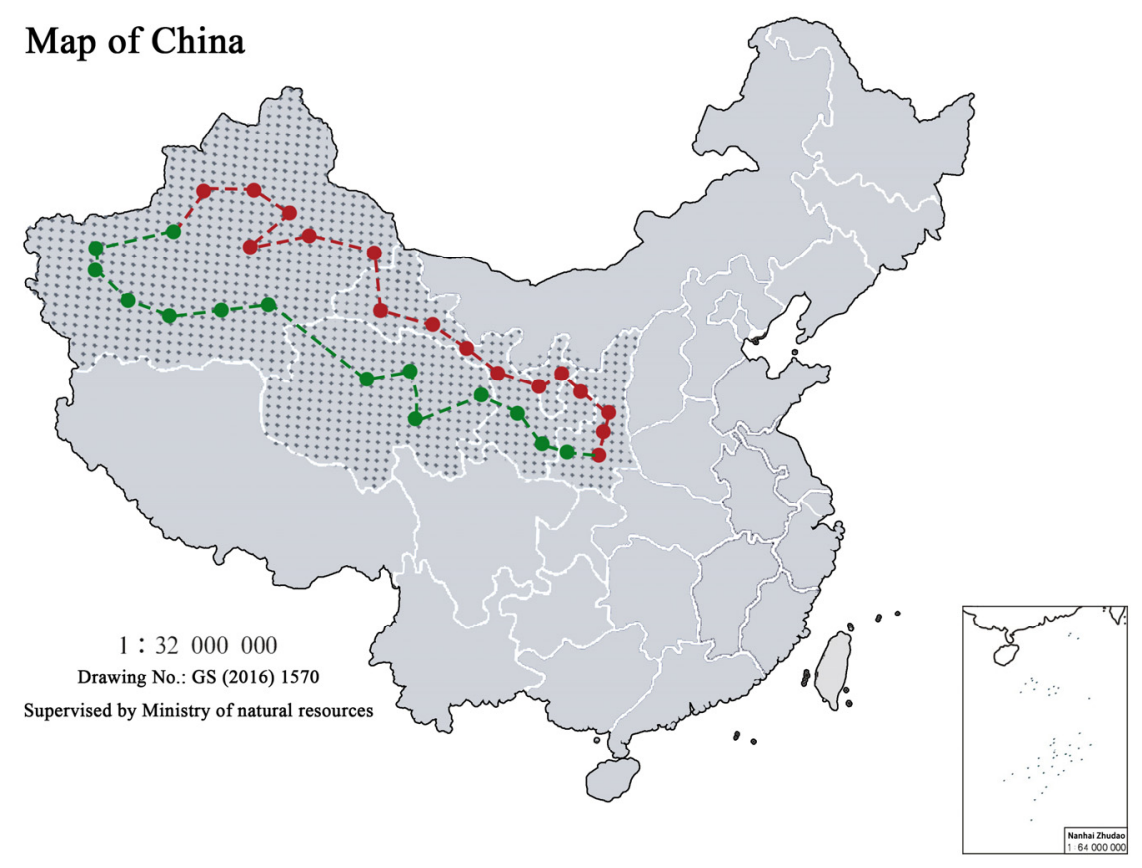

Figure 4. Schematic diagram of the overall planning of the Silk Road road trip tour routes and camping sites in China (Source: painted by the author)

emergency areas, lighting equipment, road signs, etc.; formulate a unified roadmap, scenic spots introduction, cultural and historical brochures, websites, traffic radio stations, etc.; establish a unified management system, rescue system, garbage disposal regulations, supervision system, etc. Adhere to the unity, systematicness, science, rationality and safety of planning, and build a complete and distinctive campsite system.

\subsection{Design: Macroscopic Design, Reasonable Layout}

The camp line is divided into "south line" and "north line". The southern route is about $5,181 \mathrm{~km}$ and the northern route is about 5,328 $\mathrm{km}$ (Figure 4). At the same time, according to the "average vehicle speed of $75 \mathrm{M} / \mathrm{h}$, driving about 5-6 hours a day" reference standard, the distance between the two locations is set to be about 150-300 km.

\subsection{Idea: Plan the Route with Province as the Unit and Run Through the Whole Route}

Integrate the planned routes of the five provinces with the Silk Road as a link. It runs through the entire path of the five provinces and regions along the Silk Road, and implements systematic policies and overall planning for coordination and unification. In order to enable visitors to better feel the natural landscape and cultural features of the northwest region. This plan takes the ancient Silk Road as the main line, on the basis of which a side line is extended to form two routes of the south and the north (Table 1). The two lines take Xi'an City, Shaanxi Province (ancient Guchang' an) as the starting point, each province as an independent unit, and Aksu City in Xinjiang as the end point to form a "circular" line.

Table 1. Setting Word's margins.

\begin{tabular}{|l|l|c|l|c|}
\hline \multirow{2}{*}{$\begin{array}{l}\text { Provin } \\
\text {-ces and } \\
\text { automous }\end{array}$} & \multicolumn{2}{|c|}{ South line } & \multicolumn{2}{c|}{ North line } \\
\cline { 2 - 5 } & $\begin{array}{c}\text { Starting } \\
\text { point }\end{array}$ & $\begin{array}{c}\text { Dist } \\
\text { ance } \\
\text { (km) }\end{array}$ & $\begin{array}{c}\text { Starting } \\
\text { point }\end{array}$ & $\begin{array}{c}\text { Dista } \\
\text { nce } \\
\text { (km) }\end{array}$ \\
\hline Shaanxi & $\begin{array}{l}\text { Xi'an- } \\
\text { Baoji }\end{array}$ & 210 & $\begin{array}{l}\text { Xi'an- } \\
\text { Huangling- } \\
\text { Yan'an } \\
\text {-Dingbian }\end{array}$ & 545.5 \\
\hline Gansu & $\begin{array}{l}\text { Tianshui-L } \\
\text { inxia-Lanz } \\
\text { hou }\end{array}$ & 481 & $\begin{array}{l}\text { Wuwei- } \\
\text { Zhangye- } \\
\text { Jiayuguan- } \\
\text { Dunhuang }\end{array}$ & 838.3 \\
\hline Ningxia & - & 0 & $\begin{array}{l}\text { Yinchuan-Z } \\
\text { hongwei-Gu } \\
\text { yuan }\end{array}$ & 204.7 \\
\hline \multirow{2}{*}{ Qinghai } & $\begin{array}{l}\text { Xining- } \\
\text { Madoi- } \\
\text { Touraine- } \\
\text { Delingha- } \\
\text { Golmud- } \\
\text { Mangya }\end{array}$ & 1819 & & \\
\hline & & & \\
\hline
\end{tabular}




\begin{tabular}{|l|l|l|l|l|}
\hline & Ruoqiang- & \multirow{2}{*}{1922.2} & Hami- & \multirow{2}{*}{ Turpan- } \\
Xingjiang & Qiemo- & & Korla- & \\
& Minfeng- & & Kuitun- & \\
& Hotan- & & Yining- & \\
& Yecheng- & & Aksu & \\
& Kashgar- & & & \\
& Aksu & & & \\
\hline
\end{tabular}

Of course, campsites between provinces are either adjacent or non-adjacent (Table 2).

Table 2 Route and distance planning of road trip tour in provincesof China - between provinces (Source: painted by the author)

\begin{tabular}{|c|c|c|c|c|}
\hline \multirow{2}{*}{$\begin{array}{l}\text { Line } \\
\text { Provinces and } \\
\text { autonomous regions } \\
\text { autonomous regions }\end{array}$} & $\begin{array}{c}\text { Starti } \\
\text { ng } \\
\text { point }\end{array}$ & $\begin{array}{c}\text { Dist } \\
\text { ance } \\
\text { (km) }\end{array}$ & $\begin{array}{c}\text { Starting } \\
\text { point }\end{array}$ & $\begin{array}{c}\text { Distan } \\
\text { ce } \\
\text { (km) }\end{array}$ \\
\cline { 2 - 5 } & - & 0 & $\begin{array}{c}\text { Dingbian- } \\
\text { Yinchuan }\end{array}$ & 170 \\
\hline Shaanxi-Ningxia & - & 0 & $\begin{array}{c}\text { Zhongwei } \\
\text {-Wuwei }\end{array}$ & 293 \\
\hline Ningxia-Gansu & $\begin{array}{c}\text { Lanzh } \\
\text { ou-Xi } \\
\text { ning }\end{array}$ & 224 & - & 0 \\
\hline Gansu-Qinghai & $\begin{array}{c}\text { Mang } \\
\text { ya-Ru } \\
\text { oqiang }\end{array}$ & 351 & $\begin{array}{c}\text { Dunhuang } \\
\text {-Hami }\end{array}$ & 421 \\
\hline Gansu-Xinjiang & & \multicolumn{2}{|c}{} \\
\hline
\end{tabular}

\subsection{Establish a Professional Team to Systemize the Management System and Supporting Services}

In the camp planning, it is necessary to establish a unified management and service team, introduce professional talents, and carry out professional training for personnel at different levels. At one time, the provincial and regional governments should further improve the management mechanism of campsite construction, and urge the campsite investors to carry out scientific and reasonable development and construction on the basis of following the law, so as to establish the "Silk Road Tourism" brand. Through the establishment of a unified systematic website and APP in the five provinces and regions, the unified display and sales of campsite products and campsite services will facilitate and efficiently meet the needs of self-driving travelers.

\section{CONCLUSION}

Due to the urgent demand of the public for road trip campsites and the strong desire of travelers for natural and cultural landscape in Northwest China. This paper takes the planning of the land "Silk Road" in China as the research object. After status analysis, data summary and market demand analysis, we put forward corresponding planning suggestions and overall ideas: "Persist in the promotion and display of the Silk Road culture and carry forward the Silk Road spirit; On the basis of human, valuing the nature; Unified planning, seek common development; Macroscopic design, reasonable layout; Highlight natural, humanistic and national characteristics". Only in this way can it be built into a fully functional international road trip campsite classic route. It can also lay a good foundation for promoting the economic development of the western region, and provide omprehensive services for tourists who love the "Silk Road Culture" at home and abroad.

\section{ACKNOWLEDGMENTS}

This research is supproted by the Key Project of National Social Science Fund Art Science, "Study on the Architectural Art and Folk Culture of the Traditional Dwellings along the land 'Silk Road' in China" [No. 18AH008].

\section{REFERENCES}

1.Zhai, X. N., \& Lv, J. F. (2017). Research on 1.the construction of automobile self driving camp in Liaoning Province. Economic Outlook The Bohai Sea, (2), 51-54.

2.Lin, L. J., \& Lin, G. W. (2018). Study on the development and Countermeasures of RV tourism in Hexi Corridor. Journal of Hexi University, 34(01), 66-71.

3.Ma, J. (2015). Research on the development of self driving tourism in Gansu section of the Silk Road. PhD. Dissertation. Lanzhou, Gansu: Northwest Normal University.

4.Zhu, R., \& Xue, Y. (2019). Study on camping tourism in Hexi Corridor from the perspective of inbound tourism. Journal of Glaciology and Geocryology, 41(01), 246-256.

5.Lin, S. Q., \& Wang, K. Y. (2006). Silk Road. Beijing: People's Literature Publishing House.

6.Ge, M. L., \& Li, Y. J. (2018). "Study on the planning of self driving camp in the land section of the Silk Road. Art and Technology, (5), 40-41.

7.Gao, L. A., Li, B., Liu, J. S., \& Mei, L. (2011). the development of camping tourism in European and American countries and Its Enlightenment to China. Human Geography, 26(05), 24-28. 